\title{
Kinetics and Mechanism of Catalyzed Oxidation of L-Cysteine by Salen Schiff Base Complexes of Co(III), Fe (III) and Cr(III)
}

\author{
Hamzeh M. Abdel-Halim ${ }^{1}$, Hutaf M. Baker ${ }^{2}$, Akef I. Alhmaideen ${ }^{1}$, Adnan S. Abu-Surrah ${ }^{1}$ \\ ${ }^{1}$ Department of Chemistry, The Hashemite University, Zarqa 13133, Jordan \\ ${ }^{2}$ Department of Chemistry, Al al-Bayt University, Mafraq 25113, Jordan \\ Correspondence: Hamzeh M. Abdel-Halim,Department of Chemistry, The Hashemite University, Zarqa 13133, Jordan.
}

Received: May 6, $2021 \quad$ Accepted: July 1, $2021 \quad$ Online Published: July 10, 2021

doi:10.5539/ijc.v13n2p25 URL: https://doi.org/10.5539/ijc.v13n2p25

\begin{abstract}
Kinetics of oxidation of L-cysteine by new series of substituted ONNO-donor salen-type Schiff base complexes of general formula $\left[\mathrm{M}^{\mathrm{III}}(\mathrm{L}) \mathrm{Cl}\right](\mathrm{M}=\mathrm{Co}, \mathrm{Fe}, \mathrm{Cr} ; \mathrm{L}=$ Schiff base ligand $)$ have been studied in aqueous solutions. Measurements were run at constant temperature $\left(25^{\circ} \mathrm{C}\right)$, constant ionic strength $(0.20 \mathrm{M})$, and constant $\mathrm{pH}(7.0)$ under pseudo-first order conditions, in which the concentration of cysteine is around two orders of magnitude greater than that of metal complex. The observed rate constant was determined by following the change in absorbance of reaction mixture at a predetermined wavelength with time. Results show that the rate of oxidation depends on the type of metal center, with $\mathrm{Co}$ (III) complexes were found to have the highest rates due to higher reduction potential of Co(III). The oxidation rate was also found to depend on steric factor and the electron withdrawing / releasing ability of the ligand bound to the metal ion.
\end{abstract}

Keywords: kinetics, cysteine, Salen Ligands, Co (III), Fe(III), Cr(III)

\section{Introduction}

Transition metal complexes with salicylaldimine ligands form a fundamental class of compounds in coordination chemistry. The ease of their synthesis allows the possible control on the flexibility of the backbone of the ligands, the type of the metal ion and its oxidation state and the electronic and chiral characteristics of the Shiff base salen moiety. These can play an important role as catalysts for coupling with carbon dioxide and epoxide(Jacobsen, Zhang, Loebach, Wilson, 1990) (Katsuki, Irie, Noda, Ito, Matsumoto, 1990).

Saline based complexes have been studied extensively and more than 2500 complexes have been synthesized and reported. Interest in salen type complexes was intensified in 1990 when the groups of Jacobsen and Katsuki discovered the enanothio selective epoxidation of unfunctionalized alkenes using chiral Mn(salen) complexes as catalysts( Jacobsen, Zhang, Loebach, Wilson, 1990)( Katsuki, Irie, Noda, Ito, Matsumoto, 1990). Since then, extremely wide variety of reactions catalyzed by salen complexes has been investigated. These include epoxidation of alkene(Bahramian, Mirkhani, Moghada, 2006), hydrolytic kinetic resolution of epoxides (Kureshy, et al., 2006), intermolecular hydroamination of allenes(Ayinla \& Schafer, 2006), and vinyl polymerization of norbornene(Carlini et al., 2006). Recently, the synthesis and characterization of substituted ONNO-donor salen-type Schiff base complexes of general formula $[\mathrm{MIII}(\mathrm{L}) \mathrm{Cl}](\mathrm{L}=\mathrm{Schiff}$ base ligand, $\mathrm{M}=\mathrm{Fe}, \mathrm{Co})$ has been reported by the authors (Abu-Surrah, Abdel-Halim, Abu-Shehab, Al-Ramahi, 2017).

Oxidation of L-cysteine have been the subject of several studies in recent years, using various kinetics techniques and various transition metal complexes (Jameson, Linert, Tschinkowitz, Gutmann,, 1988; Kottapalli, Adari, Vani, 2005; Laloo \& Mahanti, 1990; Lay \& Levina, 1996; Lemma Shi, Elding., 2000; Mehrotra Kapoor, Vajpai, 1984; Salomao et al., 2007; Sami Venkateshwari, Mariselvi, Mariselvi, Rajasekaran., 2010; Taube, 1970; Wang \& Stanbury, 2008). As an extension of our previous studies (Abdel-Halim, 2001; Abdel-Halim,, Abu-Surrah, and Baker 2012; Abdel-Halim,Abu-Surrah, and Baker 2010; Abdel-Halim, Abu-Surrah, and Baker, 2006; Abdel-Halim, Saleh, Khreizat, 2018; Abdel-Halim, Saleh , Khreizat., 2015; H M Abdel-Halim, Salama, Al-Burtmani, 1998; Abdel-Halim, Abu-Surrah, Qaqish, 2006; Abu-Surrah, Abdel-Halim, Al-Qaisi, 2008; Abu-Surrah, Abdel-Halim, Feda'a, 2008) on both kinetics and catalytical application, and to widen our knowledge about the oxidation of biologically important amino acids we present this work. In the present work, we report the kinetics of oxidation of L-cysteine by a new series of cobalt(III), iron(III), and chromium(III) complexes bearing substituted tetradentate Schiff base ligands. For each metal ion complex, 
the observed rate and the rate constant of reaction were determined. Effects on reaction's rates due to nature of metal center, nature and type of auxiliary groups of ligands, and the backbone structures of the complex are discussed.

\section{Experimental}

Materials: Ligands and their corresponding complexes used in the present study are shown in Figure (1). Details of the synthesis and characterizations of the ligands and their complexes are mentioned in our recent publication (Abu-Surrah, Abdel-Halim, Abu-Shehab, Al-Ramahi, 2017). Elemental analysis and Mass spectra (MS) measurements forcystine product, RSSR, were performed in our laboratories using a EURO EA 3000 and a Shimadzu-QP5050A, respectively.

Kinetic measurements: Complexes used in the present study are shown in Figure 1, numbers: 1 - 11. The ligands used for the preparation of the transition metal complexes are shown in Figure 2, numbers L1 - L6. Freshly prepared aqueous solutions of the desired concentrations of the complex and L-cysteine were used for kinetic study. Measurements were carried out using a Diode Array Spectrophotometer model 8453E from HP Agilent Technologies. Reactions were monitored by following the change in absorbance of reaction mixture with time at a predetermined wavelength, which was determined by recording the absorption spectral curves for the metal complex (TMC) alone and for its mixture with cysteine (RSH) after completion of reaction. The wavelength of maximum absorbance difference $\left(\lambda_{\operatorname{mad}}\right)$ between the absorption of TMC and the mixture was selected. Typical plot is shown in Figure (3).

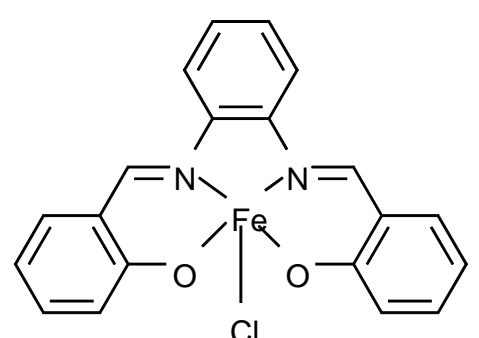

(1)

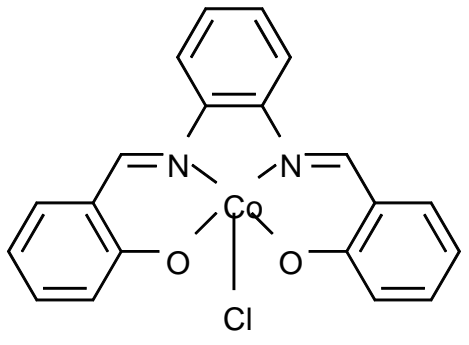

(2)

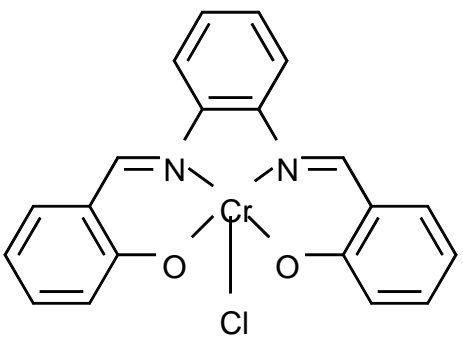

(3)

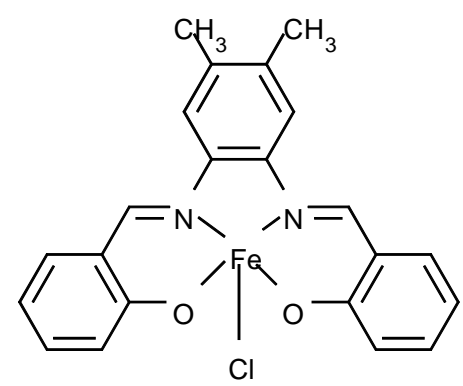

(4)

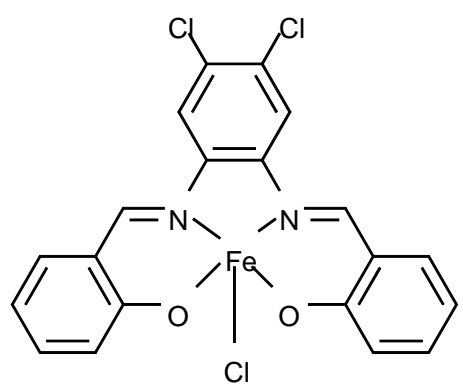

(6)<smiles></smiles>

(5)

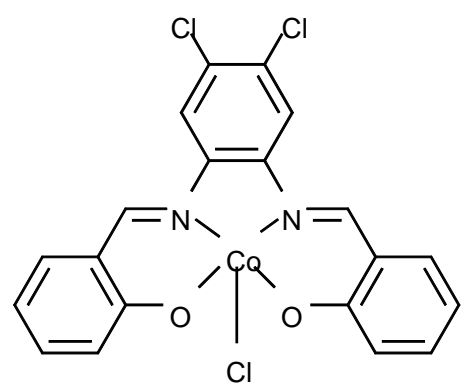

(7) 


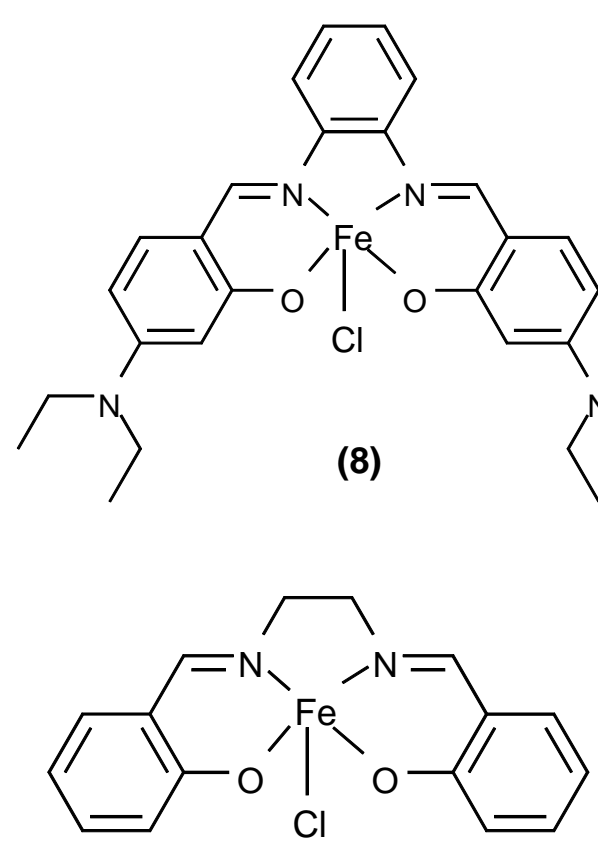

(10)

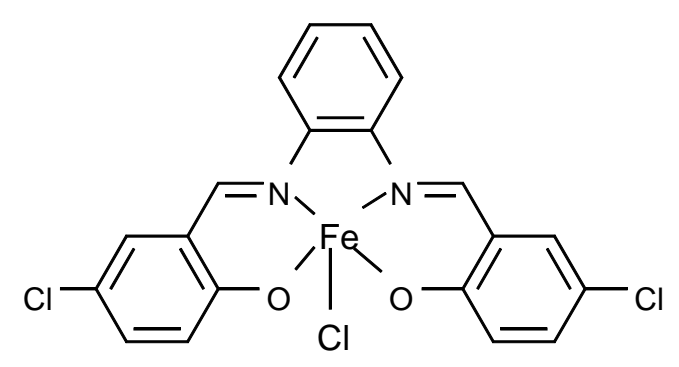

(9)

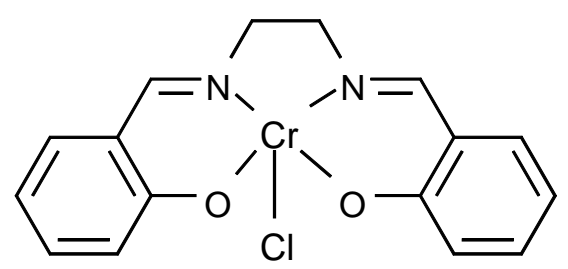

(11)

Figure 1. Structure of salen-based complexes used in the kinetic study 


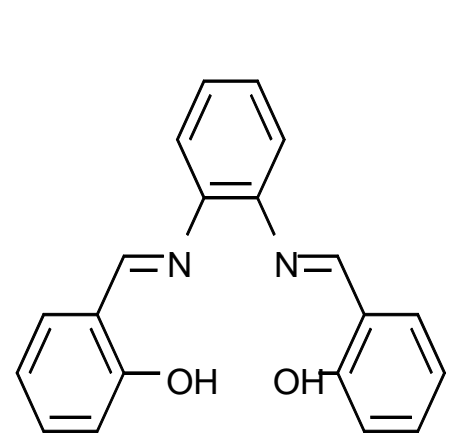

(L)<smiles>CCNCC</smiles>

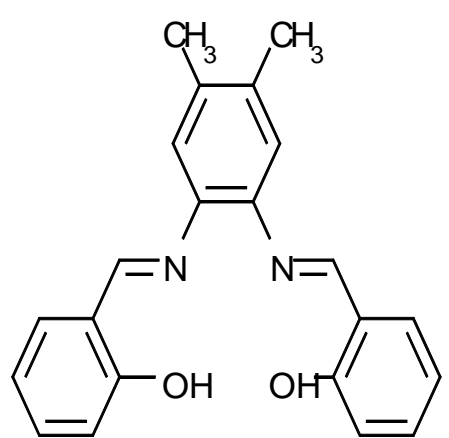

$\left(L_{2}\right)$
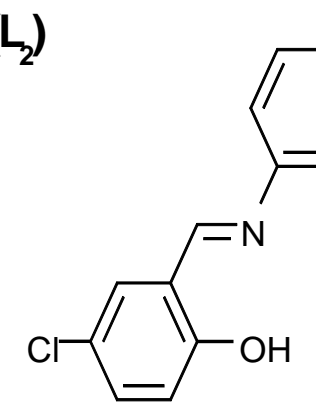<smiles>Cc1ccccc1</smiles><smiles>N=Cc1ccccc1O</smiles>

$\left(L_{3}\right)$

(L5)

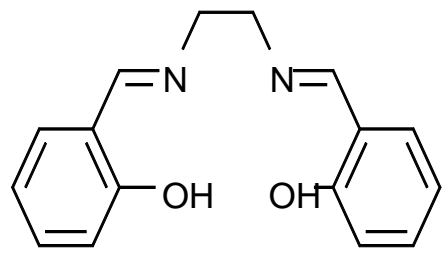

(L6)

Figure 2. Structure of Ligands used in the kinetic study 


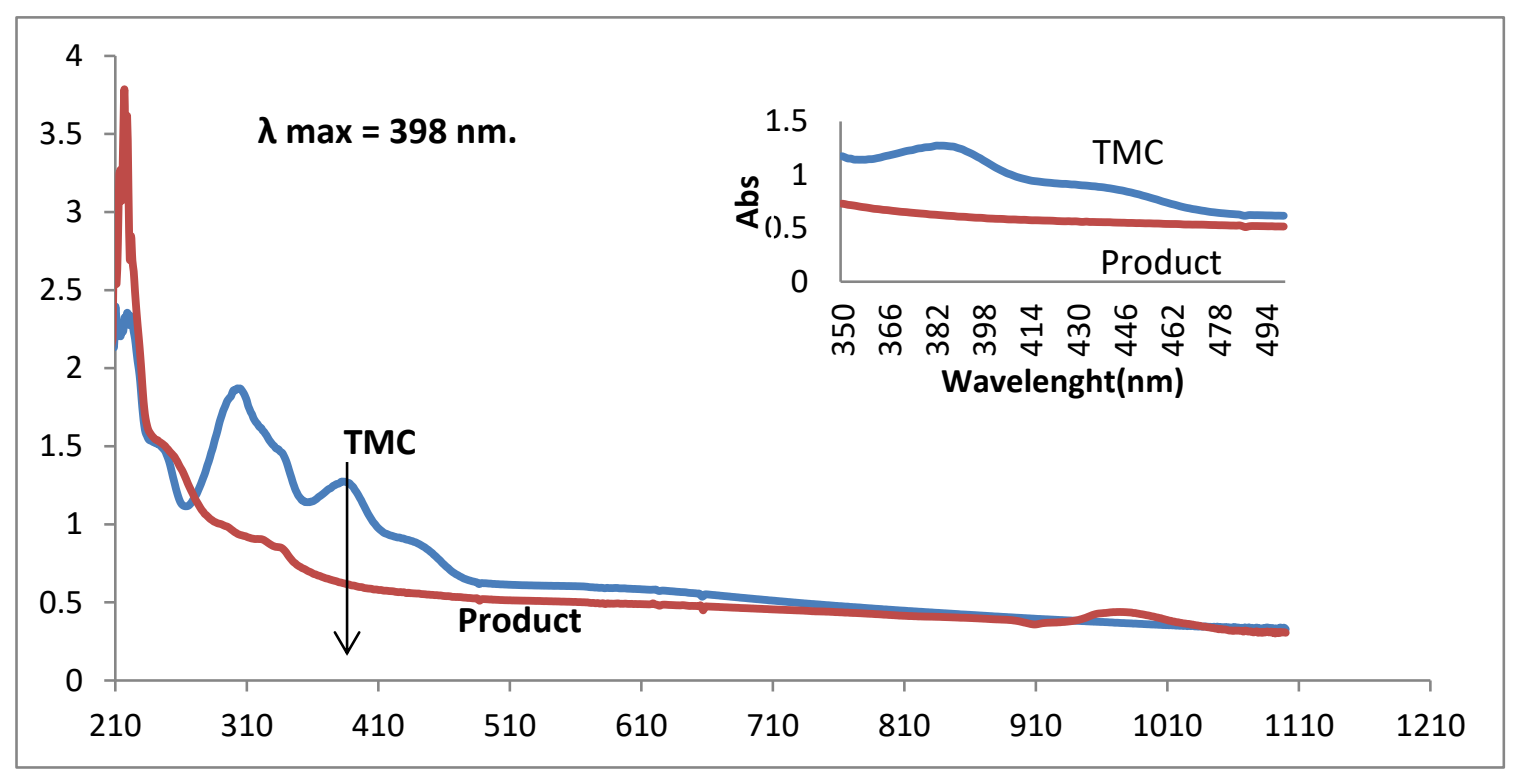

Figure 3. Plot of $\lambda$ scan for the product and for the reactant of the oxidation of cysteine by TMC(6); The arrow shows the wavelength at which kinetic experiment were studied: $\lambda_{\operatorname{mad}}=398 \mathrm{~nm}$

A list of $\lambda_{\text {mad }}$ for various complexes is shown in Table 1. All reactions were studied under pseudo-first order condition, at which the concentrations of cysteine (RSH) $\left[10^{-2}-10^{-1} \mathrm{~mol} \mathrm{dm}^{-3}\right]$ chosen to be 1-2 orders of magnitude larger than those of transition metal complex (TMC) $\left[10^{-4}-10^{-2} \mathrm{~mol} \mathrm{dm}^{-3}\right]$. Ionic strength of the solutions was kept constant at $0.20 \mathrm{~mol} \mathrm{dm}^{-3}$ using $\mathrm{NaClO}_{4}$. Temperature of solution and its $\mathrm{pH}$ were both maintained constant at $25 \pm 0.1^{\circ} \mathrm{C}$ and $7.0 \pm$ 0.1 , respectively.

Table (1). A list of $\lambda_{\operatorname{mad}}$ for various complexes

\begin{tabular}{c|c|c|c|c}
\hline $\begin{array}{c}\text { TMC } \\
\text { No. }\end{array}$ & Complex & $\begin{array}{c}\lambda_{\text {mad }} \\
(\mathbf{n m})\end{array}$ & $\begin{array}{c}\mathbf{k}_{\text {obs }} \\
\left(\mathbf{s}^{-1}\right)\end{array}$ & $\begin{array}{c}\mathbf{k} \\
\left(\mathrm{dm}^{3} \mathrm{~mol}^{-1} \mathrm{~s}^{-1}\right)\end{array}$ \\
\hline $\mathbf{1}$ & {$\left[(\mathbf{L 1}) \mathrm{Fe}^{(\mathrm{III})} \mathrm{Cl}\right]$} & 450 & slow & slow \\
\hline $\mathbf{2}$ & {$\left[(\mathbf{L 1}) \mathrm{Co}^{(\mathrm{III})} \mathrm{Cl}\right]$} & 450 & $2.23 \times 10^{-3}$ & $7.91 \times 10^{-3}$ \\
\hline $\mathbf{3}$ & {$\left[(\mathbf{L 1}) \mathrm{Cr}^{(\mathrm{III})} \mathrm{Cl}\right]$} & 443 & Very slow & Very slow \\
\hline $\mathbf{4}$ & {$\left[(\mathbf{L 2}) \mathrm{Fe}^{(\mathrm{III})} \mathrm{Cl}\right]$} & 450 & $1.48 \times 10^{-4}$ & $3.94 \times 10^{-4}$ \\
\hline $\mathbf{5}$ & {$\left[(\mathbf{L 2}) \mathrm{Co}^{(\mathrm{III})} \mathrm{Cl}\right]$} & 450 & $2.31 \times 10^{-3}$ & $8.92 \times 10^{-3}$ \\
\hline $\mathbf{6}$ & {$\left[(\mathbf{L 3}) \mathrm{Fe}^{(\mathrm{III})} \mathrm{Cl}\right]$} & 398 & $4.01 \times 10^{-5}$ & $6.17 \times 10^{-4}$ \\
\hline $\mathbf{7}$ & {$\left[(\mathbf{L 3}) \mathrm{Co}^{(\mathrm{III})} \mathrm{Cl}\right]$} & 585 & $3.56 \times 10^{-5}$ & $6.47 \times 10^{-3}$ \\
\hline $\mathbf{8}$ & {$\left[(\mathbf{L 4}) \mathrm{Fe}^{(\mathrm{III})} \mathrm{Cl}\right]$} & 445 & $7.42 \times 10^{-4}$ & $1.10 \times 10^{-3}$ \\
\hline $\mathbf{9}$ & {$\left[(\mathbf{L 5}) \mathrm{Fe}^{(\mathrm{III})} \mathrm{Cl}\right]$} & 450 & $1.72 \times 10^{-5}$ & $7.37 \times 10^{-3}$ \\
\hline $\mathbf{1 0}$ & {$\left[(\mathbf{L 6}) \mathrm{Fe}^{(\mathrm{III})} \mathrm{Cl}\right]$} & 500 & $2.27 \times 10^{-4}$ & $1.36 \times 10^{-2}$ \\
\hline $\mathbf{1 1}$ & {$\left[(\mathbf{L 6}) \mathrm{Cr}^{(\mathrm{III})} \mathrm{Cl}\right]$} & 443 & Very slow & Very slow \\
\hline
\end{tabular}

The observed rate constant, $\mathrm{k}_{\mathrm{obs}}$, and the rate constant, $\mathrm{k}$, for the oxidation of Cysteine with $\mathrm{Fe}(\mathrm{III}), \mathrm{Co}(\mathrm{III})$ and $\mathrm{Cr}(\mathrm{III})$ TMC complexes.

\section{Results and Discussion}

Oxidation of cysteine (RSH) leads to formation of cystine (RSSR), as shown below:

$$
2 \mathrm{RSH} \rightarrow \mathrm{RSSR}+2 \mathrm{H}^{+}+2 \mathrm{e}^{-}
$$

Estimation of residual oxidant suggested that two moles of cysteine consume two moles of transition metal complex (TMC), such that 


$$
2\left[\mathrm{M}^{\mathrm{III}}(\mathrm{L}-\mathrm{L})_{2} \mathrm{Cl}\right]+2 \mathrm{RSH} \rightarrow 2\left[\mathrm{M}^{\mathrm{II}}(\mathrm{L}-\mathrm{L})_{2}\right]+\mathrm{RSSR}+2 \mathrm{HCl}
$$

The rate of reaction is given by

$$
\text { Rate }=k[\mathrm{Cys}]^{\mathrm{a}}[\mathrm{TMC}]^{\mathrm{b}}
$$

Where $k$ is the reaction rate constant and (a) \& (b) are orders of reaction with respect to concentrations of Cys and TMC, respectively. Since all M(III) complexes are one-electron oxidants, then, oxidation of cysteine is expected to give a radical intermediate, as shown below:

$$
\begin{aligned}
& \mathrm{RSH} \rightleftharpoons \mathrm{RS}^{-}+\mathrm{H}^{+} \\
& \mathrm{RS}^{-} \rightarrow \mathrm{RS} \\
& 2 \mathrm{RS} \rightarrow \mathrm{RSSR}
\end{aligned}
$$

Under pseudo-first order conditions in which $[\mathrm{Cys}] \gg[\mathrm{TMC}]$, the concentration of cysteine is essentially constant throughout the reaction. Reaction rate is then given by

$$
\text { Rate } \approx-d[T M C] / \mathrm{dt}=\mathrm{k}_{\mathrm{obs}}[\mathrm{TMC}]^{\mathrm{b}}
$$

where $k_{\mathrm{obs}}$ is the observed rate constant of the reaction, given by

$$
k_{\mathrm{obs}}=k[\mathrm{Cys}]^{\mathrm{a}}
$$

Where $k$ is the rate constant for reaction (2) above.

For a first-order dependence of reaction rate on [TMC], experimental absorbance-time data pairs were fit to the exponential function:

$$
\begin{aligned}
& \left(\mathrm{A}_{\mathrm{t}}-\mathrm{A}_{\infty}\right)=\left(\mathrm{A}_{0}-\mathrm{A}_{\infty}\right) \exp \left(-k_{\mathrm{obs}} \mathrm{t}\right) \\
& \text { or, } \quad \operatorname{Ln}\left[\frac{\left(A_{t}-A_{\infty}\right)}{A_{0}-A_{\infty}}\right]=-k_{o b s} t
\end{aligned}
$$

Where $A_{t}$ is the absorbance of TMC at a given time (t) through the reaction, $A_{0}$ is its initial absorbance $(t=0)$ and $A_{\infty}$ is the final absorbance of the reaction mixture at the end of the reaction, $(t=\infty)$, at which there is no significant change in the absorbance of the mixture. The values of $k_{\mathrm{obs}} / \mathrm{s}^{-1}$, for all reactions, were obtained from a plot of $\operatorname{Ln}\left[\left(\mathrm{A}_{\mathrm{t}}-\right.\right.$ $\left.\mathrm{A}_{\infty}\right) /\left(\mathrm{A}_{0}-\mathrm{A}_{\infty}\right)$ ] versus time ( $\mathrm{t}$ ) using Eqn. (7). Straight lines with regression coefficient $\mathrm{R}^{2} \geq 0.99$ were obtained. From Eqn. (6), a plot of $\operatorname{Ln}\left(k_{\mathrm{obs}}\right)$ versus $\operatorname{Ln}\left[\right.$ Cys] was used to determine the rate constant for the reaction, $k / \mathrm{dm}^{3} \mathrm{~mol}^{-1} \mathrm{~s}^{-1}$, from the intercept, and the order of the reaction, a, with respect to [Cys] from the slope. Typical plot is shown in Figure (4). In the present study, we found that reaction rate depends on first power of concentration of both substrate and oxidant, i.e., $\mathrm{a} \approx \mathrm{b} \approx 1$. This is in agreement with previous studies (Abdel-Halim, Saleh , Khreizat, 2018; Carlini et al., 2006; Jameson, Linert, Tschinkowitz, Gutmann,, 1988; Lay \& Levina, 1996; Lemma Shi, Elding., 2000; Mehrotra Kapoor, Vajpai, 1984; Salomao et al., 2007; Wang \& Stanbury, 2008). Kinetics results: the observed rate constant, $\mathrm{k}_{\mathrm{obs}}$, and the rate constant, $\mathrm{k}$, for oxidation of L-cysteine by various TMC complexes are shown in Table (1).

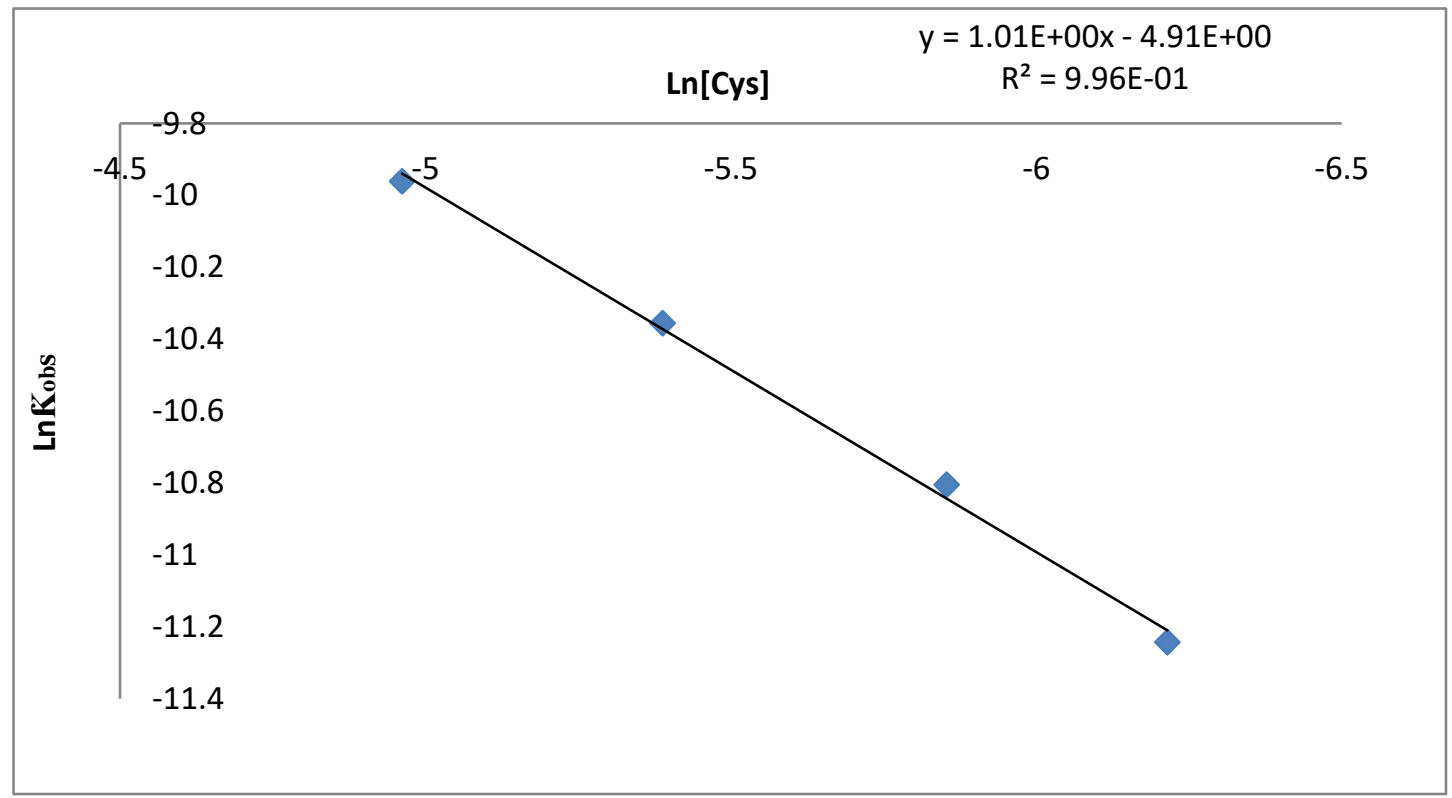

Figure 4. Plot of Ln $\mathrm{k}_{\mathrm{obs}}$ vs. Ln [cysteine] for the oxidation of cysteine by TMC(9) 
$[\mathrm{TMC}(9)]=1 \times 10^{-4} \mathrm{M} ; \mathrm{a}=1.01 ; \mathrm{k}=7.37 \times 10^{-3} \mathrm{dm}^{3} \mathrm{~mol}^{-1} \mathrm{~s}^{-1}$.

Table (1) shows a wide variation in the oxidation rate of cysteine by the various complexes. The rate of electron transfer in a complex: $\left(\mathrm{ML}_{\mathrm{n}}\right)^{\mathrm{m}+}+\mathrm{e}^{-} \rightarrow\left(\mathrm{ML}_{\mathrm{n}}\right)^{(\mathrm{m}-1)+}$, should depend on both the nature of the metal center and nature of the ligand attached in the TMC.

Kinetic results in Table (1) show different rates for different TMC metal centers. Different metal centers have different electrode potential. We see that TMC complexes 1-3 having the same ligand (L1) but different transition metal core. The rate constant, $\mathrm{k}$, for $\mathrm{Co}$ (III) complex is higher than that for $\mathrm{Fe}(\mathrm{III})$, which is in turn higher than that for $\mathrm{Cr}$ (III) complex. This can be explained by the fact that the standard electrode potential for $\mathrm{Co}$ (III) $\rightarrow \mathrm{Co}$ (II) $\left(\mathrm{E}^{0}=+1.81 \mathrm{~V}\right)$, is higher than that for $\mathrm{Fe}(\mathrm{III}) \rightarrow \mathrm{Fe}(\mathrm{II})\left(\mathrm{E}^{0}=+0.77 \mathrm{~V}\right)$ and much higher than that for $\mathrm{Cr}(\mathrm{III}) \rightarrow \mathrm{Cr}(\mathrm{II})\left(\mathrm{E}^{0}=-0.41 \mathrm{~V}\right)$. The same trend is observed for TMC pairs (4) and (5). Both have the same ligand (L2) but different transition metal centers (Fe and Co). The rate constant for TMC(5) is more than ten times faster than that for TMC(4). Similarly, for TMC pairs (6) and (7) both having the same ligand (L3) but different transition metal centers (Fe and Co). The rate constant for TMC(7) is ten time faster than that for TMC(6). Also, comparing the rate constants for the TMC pairs (10) and (11), both having the same ligand (L6) but different transition metal centers ( $\mathrm{Fe}$ and $\mathrm{Cr}$ ), the rate for TMC(10) is faster than that for TMC(11).

Regarding the nature of the ligand in the TMC we see that it plays an important role in the oxidation process. Deciding which mechanism the oxidation process proceeds via may be difficult. If ligand in the complex has extra lone pair(s) to form "links" with cysteine and/or if the geometry around the metal center have enough space for cysteine to bind to this ligand, then the reaction is more likely to proceed via an inner-sphere mechanism (Carlini et al., 2006). In this case, a substitution reaction occurs that produces cysteine and TMC linked together. Then, a transfer of an electron in the oxidation process occurs followed by separation of the products. On the other hand, if the ligand has noextra lone pairs with which to form bonds to cysteine, or when there is a "closed" or crowded geometry around metal center, the ligands are tightly held and there is no change in the coordination sphere on the reaction. In this case, the reaction proceeds by outer-sphere electron transfer mechanism (Atkins \& Overton, 1999; Miessler \& Tarr, 1991).

Due to the availability of a vacant site of the penta coordinated complex for cysteine to approach, we believe that all reactions studied in the present work proceed via an inner-sphere mechanism. The ligand substitution occurs through an associative mechanism, which involves formation of an intermediate that includes removal of the chlorides in the TMC and forming RSSR. The reaction first proceeds by replacement of the chloride ion by a cysteine anion. This step is too fast to be measured on our instrument. A reductive elimination is then occurs to form the square planner M(II) complex, and a white precipitate indicates the formation of cystine(RSSR), as shown in Eqn. (2) above. This step is believed to be the rate-determining step. And its rate is what we intend to measure in the present work. The final products were isolated and characterized. The white precipitate was characterized by EA to be RSSR (calcd. C 29.99, H 5.03, N 11.66, S 26.69; found C 30.01, H 4.88, N 10.99, S 26.06), and mass spectroscopy (GC)( MS (EI, 70 eV): m/z (\%) = 243 [M+], 76). This proves the formation of RSSR, which supports the suggested mechanisms for the reaction, as shown in Scheme 1.

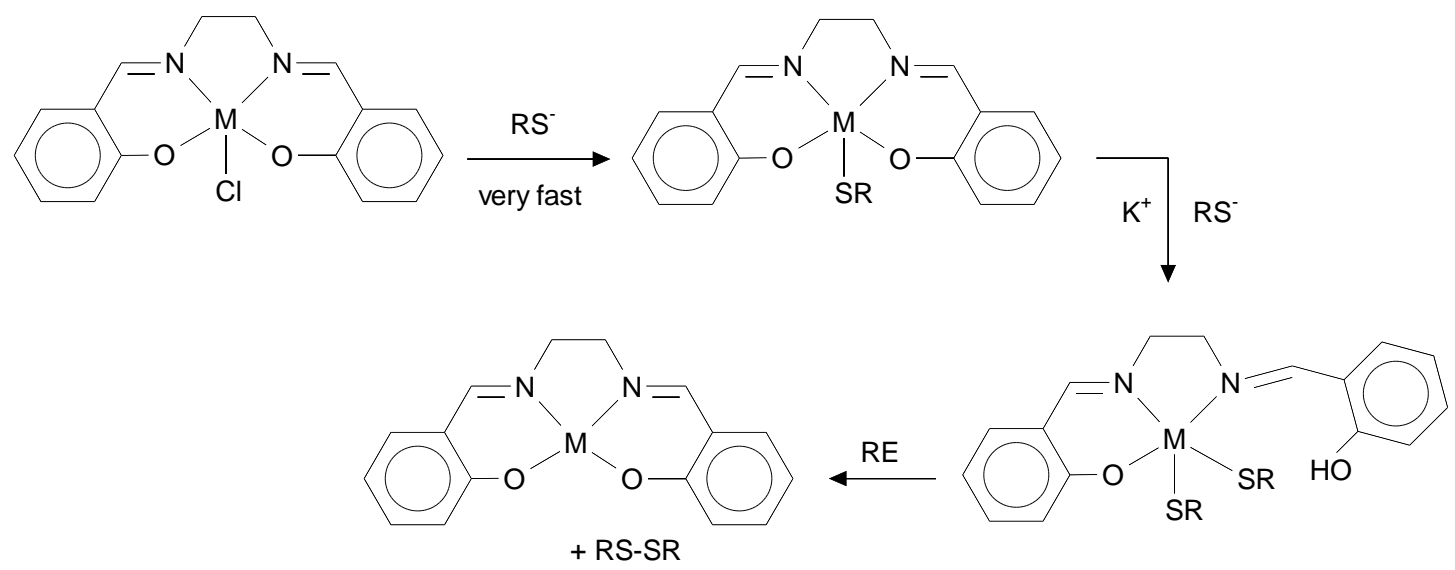

Scheme 1. The proposed mechanism for the oxidation of cysteine by the TMC salencomplexes

For Schiffsalen based complexes, with two donor atoms $\mathrm{N}$ and $\mathrm{O}$, they exert different electronic effects on the transition metal complex. The phenolate oxygen is known to be a hard electron donor, which stabilizes the higher oxidation state of metal center, while the imine nitrogen is a soft electron donor that stabilizes the lower oxidation state of the metal. Therefore, the rate of electron transfer from Cys to $\mathrm{M}(\mathrm{III})$ should depend on the nature of ligand regarding its electron donating / withdrawingability in addition to the stearic factor related to the size of the ligand. Ligands with $\pi$ electrons $(\pi-$ 
donors or $\pi$-acceptors) provide better pathways for tunneling, and hence facilitate the reduction process. Therefore, it is expected that redox reaction rate should be faster with $\pi$-electrons ligand than with $\sigma$-donor ligands, or ligand with no extra lone pairs and no low-lying antibonding orbitals. However, the rate of electron transfer through ligands with strong $\pi$ acceptor effect is expected to be slower than the transfer rate through weaker $\pi$-acceptor ligands or $\pi$-donor ligands. The presence of vacant $\pi^{*}$ in strong $\pi$-acceptor ligands makes electron transfer harder. This is due to the possibility of the electron getting "trapped" or "captured", momentarily, in the vacant $\pi^{*}$ of the ligand. This is unlikely to occur in electrons "rich" $\pi$, or $\sigma$-donor ligands. Due to the possibility of back bonding, strong $\pi$-acceptors are also strong ligands.

The salen-based complexes used in the kinetic study all have square pyramidal structure (Figure 1). For a square pyramidal symmetry of the salen-based complexes, splitting in the d-orbitals depends on the ligand's strength. For a strong ligand with high splitting, the donated electron from cysteine, goes to the higher energy orbitals. This should be more difficult and less probable to occur than donation to the lower energy t2g orbitals for weak ligand. Therefore, one can conclude that the electrode potential of the metal ion becomes less positive, hence the redox rate should decrease as the ligand strength in the spectrochemical series increases.

The second factor that affects the reduction potential of $\mathrm{M}^{3+}$, and hence the rate of the redox reaction, is the size of the ligand. As mentioned above, the rate of reduction of the metal ion in the complex depends on the ability of the electron to tunnel through the ligand. The probability of an electron to tunnel through the ligands is a quantum mechanical property, which can be calculated from time-dependent perturbation theory.

Using Gamow equation, Abdel-Halim(Hamzeh M. Abdel-Halim, 2001) derived a formula, which correlates the size of the ligand to the transition probability. The probability of transfer, $\kappa$, for an electron leaking through a potential energy barrier across the ligand around the central metal ion is given by

$$
\kappa=\exp \left\{-(8 \pi \mathrm{d} / 3 \mathrm{~h})[2 \mathrm{~m}(\mathrm{U}-\mathrm{W})]^{1 / 2}\right\}
$$

where $\kappa$ is known as the transmission coefficient, $U$ is the height of the potential barrier, $W$ is the kinetic energy of the electron, $\mathrm{m}$ is the electron mass, and $\mathrm{d}$ is the width of the barrier at the height of penetration. As an approximation, one may consider $U$ to represent the potential of an electron moving in the coulomb field of two ions. Therefore, $U$ is given by the coulomb equation

$$
U=\frac{q_{1} q_{2}}{D d}-\frac{e q_{1}}{D x}-\frac{e q_{2}}{D(d-x)}
$$

where $q_{1}$ and $q_{2}$ are the charges of each of the ions $\mathrm{M}(\mathrm{III})$ complex and cysteine, respectively, $\mathrm{D}$ is the dielectric constant of the solvent, and $(\mathrm{x})$ is the distance the electron has to travel from the electron donor (cysteine) to the center of the electron acceptor (M(III)). This distance depends on the size of the ligand around the central metal ion.

The net charge on cysteine, $q_{2}$, is zero.Therefore, equation (9) reduces to the simple form

$$
U=-\frac{e q_{1}}{D x}
$$

Equations (8) and (10) show that, for all other factors being the same, as size of the ligand in the complex increases, transmission coefficient and hence the rate constant should decrease.

Looking at TMC's studied and ligands used (Figures $1 \& 2$ ),kinetic results show that the reaction rate constant among iron complexes increases in the order: $\left[(\mathbf{L 6}) \mathrm{Fe}^{(\mathrm{III})} \mathrm{Cl}\right](10)>\left[(\mathbf{L 5}) \mathrm{Fe}^{(\mathrm{III})} \mathrm{Cl}\right](9)>\left[(\mathbf{L} \mathbf{4}) \mathrm{Fe}^{(\mathrm{III})} \mathrm{Cl}\right](8)>\left[(\mathbf{L 3}) \mathrm{Fe}^{(\mathrm{III})}\right.$ $\mathrm{Cl}](6)>\left[(\mathbf{L 2}) \mathrm{Fe}^{(\mathrm{III})} \mathrm{Cl}\right](4)>\left[(\mathbf{L 1}) \mathrm{Fe}^{(\mathrm{III})} \mathrm{Cl}\right](1)$. Looking at ligands $\mathrm{L} 6$ with $\mathrm{L} 5$, we see that $\mathrm{L} 5$ has 2 chlorides and a benzene ring, which pulls electrons towards them making electron transfer to $\mathrm{M}(\mathrm{III})$ harder and the rate for TMC(9) to be slower than that for TMC(10).

Comparing TMC(9) with TMC(8), we see that the rate of oxidation of cysteine by TMC(9) is higher than that for TMC(8). Here, the size of the ligand plays the important role. The size of L4 is bigger than that for L5, hence the rate is slower according to Eqn. (8) above.

Comparing TMC(8) with TMC(6), we see, as mentioned before, the presence of two Cl's on the benzene ring of L3 make the oxidation process slower, and hence, the rate of oxidation of cysteine by $\mathrm{TMC}(6)$ is slower than that with TMC(8).

The presence of two bulky $\mathrm{CH}_{3}$ groups on the Benzene ring of $\mathrm{L} 2$ make the oxidation process with $\mathrm{TMC}(4)$ slower than that for TMC(6). Finally, comparing the rates of TMC(4), with L2 ligand,and TMC(1), with L1 ligand, we see that the 
rate is higher for TMC(4) than that for TMC(1). This can be explained by the presence of two electron donating $\mathrm{CH} 3$ groups in L2 that facilitate the oxidation process of cysteine and making the rate faster. Here, the electronic factor plays the more important role.

Looking at rates of oxidation of cysteine by $\mathrm{Co}(\mathrm{III})$ complexes: TMC(2), TMC(5) and TMC(7), with ligands L1, L2 and L3, respectively, we observe that their rates are approximately equal, within experimental errors. The high standard reduction potential for $\mathrm{Co}(\mathrm{III}) \rightarrow \mathrm{Co}(\mathrm{II}),\left(\mathrm{E}^{0}=+1.81 \mathrm{~V}\right)$ indicates that the effect of reduction potential of the metal ion is more important than the effect of the nature of the ligand.

In summary, one may conclude that the rate of oxidation of cysteine by different transition metal complexes is found to depend directly on the electrode potential of the metal ion center, and the nature of the ligand regarding its size and its electron releasing / withdrawing ability. The effect of the metal electrode potential is found to be predominant factor that determines the rate of the reaction.

\section{References}

Abdel-Halim, \&Hamzeh M. (2001). Journal of Chemical Society of Pakistan, 23(2), 69-73.

Abdel-Halim, H M, Salama, S. B., \& Al-Burtamani, S. K. (1998). Pakistan Journal of Scientific and Industrial Research, 41(2), 71-74.

Abdel-halim, H. M., Abu-surrah, A. S., \& Qaqish, S. E. (2006). Kinetics of Oxidation of L-Cysteine by Transition Metal Complexes. Asian Journal of Chemistry, 18(2), 947.

https://www.asianjournalofchemistry.co.in/user/journal/viewarticle.aspx?ArticleID=18_2_28

Abdel-Halim, H.M. (2001). International Jour. Chem., 11, 131.

Abdel-Halim, Hamzeh M, Abu-Surrah, A. S., \& Baker, H. M. (2006). Kinetics of the Oxidation of L-Cysteine by transand cis-Cobalt(III) and Iron(III) Complexes. Zeitschrift Für Naturforschung B, 61(11), 1346-1350.

https://doi.org/10.1515/znb-2006-1105

Abdel-Halim, Hamzeh M, Abu-Surrah, A. S., \& Baker, H. M. (2010). Kinetics of Oxidation of L-Cysteine by trans- and cis-CoIII and FeIII Complexes based on $\alpha$ - and $\gamma$-Diimine Schiff Base Ligands. Z. Anorg. Allg. Chem., 2010, 636, 872. https://doi.org/10.1002/zaac.200900480

Abdel-HalimaHamzeh, M., Abdullah, I. S., \& Sanad, K. K. (2018). Kinetics of Oxidation of L-Cysteine by Transition Metal Complexes. Asian J. Chem., 30. https://doi.org/10.14233/ajchem.2018.21463

Abu-Surrah, A. S., Abdel-Halim, H. M., \& Al-Qaisi, F. M. (2008). Trans- and cis- Cobalt(III), Iron(III), and Chromium(III) Complexes Based on $\alpha$ - and $\gamma$-Diimine Schiff Base Ligands: Synthesis and Evaluation of the Complexes as Catalysts for Oxidation of L-Cysteine. Zeitschrift Für Anorganische Und Allgemeine Chemie, 634(5), 956-961. https://doi.org/10.1002/zaac.200700578

Abu-Surrah, A. S., Abdel-Halim, H. M., \& Feda'a, M. (2008). Synthesis of Cobalt(III), Iron(III), and Chromium(III) Complexes with Salicylaldiminato Ligands: Evaluation of the Complexes as Catalysts for Oxidation of L-Cysteine. Zeitschrift Für Naturforschung B, 63(7), 848-852. https://doi.org/10.1515/znb-2008-0707

Abu-Surrah, A. S., Abdel-Halim, H. M., Abu-Shehab, H. A. N., \& Al-Ramahi, E. (2017). Iron and cobalt salicylaldimine complexes as catalysts for epoxide and carbon dioxide coupling: effects of substituents on catalytic activity. Transition Metal Chemistry, 42(2), 117-122. https://doi.org/10.1007/s11243-016-0113-9

Atkins, P., \& Overton, T. (1999). Shriver and Atkins' inorganic chemistry. Oxford University Press, USA.

Ayinla, R. O., \& Schafer, L. L. (2006). Bis(amidate) titanium precatalyst for the intermolecular hydroamination of allenes. Inorganica Chimica Acta, 359(9), 3097-3102. https://doi.org/10.1016/j.ica.2005.12.041

Bahramian, B., Mirkhani, V., Moghadam, M., \& Tangestaninejad, S. (2006). Manganese (III) salen immobilized on montmorillonite as biomimetic alkene epoxidation and alkane hydroxylation catalyst with sodium periodate. Catalysis Communications, 7(5), 289-296. https://doi.org/10.1016/j.catcom.2005.11.016

Carlini, C., Giaiacopi, S., Marchetti, F., Pinzino, C., Raspolli Galletti, A. M., \& Sbrana, G. (2006). Vinyl Polymerization of Norbornene by Bis(salicylaldiminate)copper(II)/Methylalumoxane Catalysts. Organometallic, 25, 15, 3659-3664. https://doi.org/10.1021/om060173i

Hamzeh, M. Abdel-Halim. (2012). Kinetics of Oxidation of L-Cysteine by Cobalt (III), Iron(III), and Chromium(III) Complexes of Salicylaldiminato Ligands. Jordan Journal of Chemistry, 7(1), 33-40. https://jjc.yu.edu.jo/index.php/jjc/article/view/224

Irie, R., Noda, K., Ito, Y., Matsumoto, N., \& Katsuki, T. (1990). Catalytic asymmetric epoxidation of unfunctionalized 
olefins. Tetrahedron Letters, 31(50), 7345-7348. https://doi.org/10.1016/S0040-4039(00)88562-7

Jameson, R. F., Linert, W., Tschinkowitz, A., \& Gutmann, V. (1988). Anaerobic oxidation of cysteine to cystine by iron(III). Part 2. The reaction in basic solution. Journal of the Chemical Society, Dalton Transactions, 8, 943-946. https://doi.org/10.1039/DT9880002109

Kottapalli, K. K., Adari, K. K., Vani, P., \& Govindan, S. K. (2005). Mechanism of Oxidation of L-Cysteine by Hexachloroiridate(IV) - A Kinetic Study. Transition Metal Chemistry, 30(7), 773-777. https://doi.org/10.1007/s11243-005-4827-3

Laloo, D., \& Mahanti, M. K. (1990). Kinetics of oxidation of amino acids by alkaline hexacyanoferrate(III). Journal of Physical Organic Chemistry, 3(12), 799-802. https://doi.org/10.1002/poc.610031205

Lay, P. A., \& Levina, A. (1996). Kinetics and Mechanism of Chromium(VI) Reduction to Chromium(III) by 1-Cysteine in Neutral Aqueous Solutions. Inorganic Chemistry, 35(26), 7709-7717. https://doi.org/10.1021/ic960663a

Lemma, K., Shi, T., \& Elding, L. I. (2000). Kinetics and Mechanism for Reduction of the Anticancer Prodrug trans, trans, trans-[PtCl2(OH)2(c-C6H11NH2)(NH3)] (JM335) by Thiols. Inorganic Chemistry, 39(8), 1728-1734. https://doi.org/10.1021/ic9913511

Mehrotra, R. N., Kapoor, R. C., \& Vajpai, S. K. (1984). Kinetics and mechanisms of redox reactions in aqueous solution. Part 8. Osmium(VIII) catalysed oxidation of amino acids by alkaline hexacyanoferrate(III). Journal of the Chemical Society, Dalton Transactions, 6, 999-1003. https://doi.org/10.1039/DT9840000999

Miessler, G. L., \& Tarr, D. A. (1991). Inorganic Chemistry, 471 New Jersey. Prentice Hall.

Saleh, A. I., Al-Ghreizat, S. K., \& Abdel-Halim, H. M. (2015). Kinetics of Oxidation of Atropine by Alkaline KMnO4 in Aqueous Solutions. Asian Journal of Chemistry, 27(10). https://doi.org/10.14233/ajchem.2015.19039

Salomao, G. C., Olsen, M. H. N., Drago, V., Fernandes, C. Filho, L. C., \& Antunes, O. A. C. (2007). Oxidation of cyclohexane promoted by $[\mathrm{Fe}(\mathrm{III})(\mathrm{Salen}) \mathrm{Cl}]$ and $[\mathrm{Mn}(\mathrm{III})(\mathrm{Salen}) \mathrm{Cl}]$. Catalysis Communications, 8, 69. https://doi.org/10.1016/j.catcom.2006.05.021

Sami, P., Venkateshwari, K., Mariselvi, N., Sarathi, A., \& Rajasekaran, K. (2010). Studies on electron transfer reactions: reduction of heteropoly 10-tungstodivanadophosphate by 1-cysteine in aqueous acid medium. Transition Metal Chemistry, 35(2), 137-142. https://doi.org/10.1007/s11243-009-9306-9

Taube, H. (1970). Electron transfer reactions of complex ions in solution. Academic Press, New York. https://doi.org/10.1016/B978-0-12-683850-3.50008-X

Wang, X., \& Stanbury, D. M. (2008). Direct Oxidation of 1-Cysteine by [FeIII(bpy)2(CN)2]+ and [FeIII(bpy)(CN)4]-. Inorganic Chemistry, 47(3), 1224-1236. https://doi.org/10.1021/ic701891m

Zhang, W., Loebach, J. L., Wilson, S. R., \& Jacobsen, E. N. (1990). Enantioselective epoxidation of unfunctionalized olefins catalyzed by salen manganese complexes. Journal of the American Chemical Society, 112(7), 2801-2803. https://doi.org/10.1021/ja00163a052

\section{Copyrights}

Copyright for this article is retained by the author(s), with first publication rights granted to the journal.

This is an open-access article distributed under the terms and conditions of the Creative Commons Attribution license (http://creativecommons.org/licenses/by/4.0/). 